\title{
Enhancement of soil engineering properties with sewage sludge ash
}

\begin{abstract}
A laboratory study was conducted to enhance the engineering properties of soil with sewage sludge ash (SSA) that can be used in different engineering applications. Proctor compaction test was conducted to determine the optimum moisture content and maximum dry density of soil samples with arbitrarily selected SSA contents. Atterberg limits and grain size distribution tests were conducted to classify the soil. An unconfined compressive strength test was conducted with air-dry for a few arbitrarily selected curing periods to determine the strength. It was concluded from this study that the addition of SSA enhanced the soil type as well as the engineering properties. The optimum soil to SSA mixture was a mixture of soil with $7.5 \%$ SSA for a curing period of 28 days, which is expected to perform better as engineering materials. A mixture of soil with 5\% SSA content for the same curing period could also be used as a viable alternative. The addition of SSA with soil decreased the plasticity index that indicated a more pronounced reduction in volumetric swelling. The study revealed that potentially $7.5 \%$ of SSA can be used as a part of soil property improvement that would go to landfills to be managed otherwise.
\end{abstract}

Keywords: sewage sludge ash, soil engineering properties, beneficial use of SSA
Volume 5 Issue 5 - 2020

\author{
Karim MA,' Ahmed Sami Hassan, ${ }^{2}$ Ammar \\ $\mathrm{Hawa}^{3}$ \\ 'Department of Civil and Environmental Engineering, Kennesaw \\ State University, Georgia \\ ${ }^{2}$ Civil Engineer (EIT), USACE, Lake Isabella DSMP Engineering \\ Section (CESPK-ED-G), USA \\ ${ }^{3}$ Undergraduate Student, Department of Civil and \\ Environmental Engineering, Kennesaw State University, Georgia
}

Correspondence: M.A. Karim, Department of Civil and Environmental Engineering, Kennesaw State University, Marietta Campus, 655 Arntson Drive, Marietta, GA 30060, Georgia, Phones 470-578-5078/804-986-3120,

Emailmkarim4@kennesawedu/makarim@juno.com

Received: August 27, 2020 | Published: October 19, 2020

\section{Introduction}

Sewage sludge ash (SSA) is the by-product produced during the combustion of dewatered sewage sludge in an incinerator. Sewage sludge ash is primarily a silty material with some sand-size particles. The specific size range and properties of the sludge ash depend to a great extent on the type of incineration system and the chemical additives introduced in the wastewater treatment process. Most of the sludge ash generated in the United States is presently landfilled. ${ }^{1}$ Due to the relatively small quantities of sludge ash generated, provisions for ash storage will be required to accumulate sufficient amounts for most applications. The chemical properties of SSA depend on the nature of the wastewater and the chemicals used in the treatment, sludge handling, and incineration process. Since sludge is almost always dewatered prior to combustion, pretreatment of the sludge to enhance the dewatering process may include the addition of ferrous salts, lime, organics, and polymers. Ash produced at treatment plants that introduce ferrous salts or lime for sludge conditioning and dewatering contain significantly higher quantities of ferrous and calcium, respectively than that of the plants that do not. The $\mathrm{pH}$ of sludge ash can vary between values 6 and 12, but sludge ash is generally alkaline. Sludge ash from multiple hearth incinerators will usually consist primarily of silty material mixed with some larger sand-sized particles. Approximately 80 percent of the incinerators used in the United States are multiple hearth incinerators. ${ }^{1}$ The formation of larger particles is normally the result of higher operating temperatures and the formation of clinkers. Fluidized bed furnaces produce only a very fine (silt-sized) ash. The 40 CFR Part 503 (the Rule or Regulation), Standards for the Use or Disposal of Sewage Sludge, establishes standards, which consist of general requirements, pollutant limits, management practices, and operational standards, for the final use or disposal of sewage sludge generated during the treatment of domestic sewage in a treatment works.
Prior to 1998 sewage sludge was disposed of at sea or at the ocean and this type of sludge disposal is nowadays forbidden and sludge deposits in landfills are to be phased out, even though $35-45 \%$ of the sludge in Europe is still deposited. ${ }^{2}$ The main options for sludge disposal are now in the landfill, agricultural use to improve soil, sludge drying and incineration. ${ }^{3}$ Several researches investigated the beneficial use of SSA: such as potential land reclamation materials, ${ }^{4}$ building materials manufacturing, e.g., production bricks, concrete, and tiles, ${ }^{5,6}$ a raw material for cement production, ${ }^{7-9}$ aggregates for concrete, mortar, and hot mix asphalt, ${ }^{10-14}$ a component of the synthesis of lightweight materials and a substitute for sand and/or cement in cement stabilized bases, subbases and embankments in road constructions, ${ }^{13}$ and a soil stabilizer along with cement and Nanoaluminum oxide. ${ }^{15,16}$

SSA is formed from the $\sim 30 \%$ by mass of inorganic matter present in sewage sludge. The incineration of sewage sludge produces a fine powder that may contain some sand-sized particles, with negligible residual organic matter, in case of complete combustion, and low moisture. ${ }^{17}$ Al-Sharif and Attom ${ }^{17}$ conducted a laboratory study for different percentages of burned sludge ash mixed with three different types of clay soil by dry weight of clayey soils. They conducted the Atterberg limits test, unconfined compressive strength test, standard proctor density test, and swelling pressure test. Their results showed that the addition of $7.5 \%$ of SSA increased the unconfined compressive strength and maximum dry density, decreased the swelling pressure, and the swell potential of the soil. SSA addition higher than $7.5 \%$ decreased both the maximum dry density and the unconfined compressive strength and as a result, it showed less effectiveness in stabilizing the soil.

Chen and $\operatorname{Lin}^{15}$ studied the stabilization of soft subgrade soil by sewage sludge ash and cement, the results showed that the unconfined compressive strength of specimens with the SSA/cement addition was 
improved to approximately 3-7 times better than that of the untreated soil; furthermore, the swelling behavior was also effectively reduced as much as $10-60 \%$. In some samples, the SSA/cement additive improved the California Bearing Ratio (CBR) values by up to 30 times that of untreated soil. Luo et al. ${ }^{16}$ concluded that $15 \%$ of SSA/ cement replacement could effectively stabilize A- 6 clay soil, and $1 \%$ of nano- $\mathrm{Al}_{2} \mathrm{O}_{3}$ additive may be the optimum amount to add to the soil.

Lin et al. ${ }^{18}$ conducted a laboratory study to improve the properties and strength of soil, sewage sludge ash (SSA) and hydrated lime are applied to stabilize soft cohesive subgrade soil. Five different ratios (in weight percentage), $0 \%, 2 \%, 4 \%, 8 \%$, and $16 \%$, of sludge ash/ hydrated lime were used for mixture with cohesive soil. Test results indicated that the unconfined compressive strength of specimens with additives increased from three to seven times better than that of the untreated soil, and swelling behaviors were also effectively reduced for those specimens. Results of tri-axial compression test indicated that the shear strength parameter, $c$, rose with an increased amount of additives and improved from 30 to $50-70 \mathrm{kPa}$, and on the whole,
SSA/hydrated lime improved the geotechnical properties of cohesive subgrade soil.

Based on the literature review provided above, it appears that very few studies were conducted to improve soil properties with SSA for engineering uses. This study explored the possibility of using SSA to enhance the engineering properties of soil and the use of the improved soil in engineering applications. This study also explored the beneficial use of SSA that would provide an eco-friendly environment.

\section{Materials and methods}

Primarily, sludge ash consists of silica, iron, and calcium. The composition of the ash can vary significantly as previously noted and depends mainly on the additives used in the sludge conditioning operation. There is no specific data available related to the pozzolanic or cementation properties of sludge ash. However, sludge ash is not expected to exhibit any measurable pozzolanic or cementations properties. Table 1 lists the range of major element oxide concentrations found in sewage sludge ash by several researchers.

Table IThe typical range of elemental oxide concentrations in sewage sludge ash

\begin{tabular}{|c|c|c|c|c|c|}
\hline \multirow{2}{*}{ Element } & \multirow{2}{*}{ Oxide } & \multicolumn{4}{|l|}{ Concentrations (\%) } \\
\hline & & As elemental conc. ${ }^{10}$ & As oxides ${ }^{5}$ & As oxides ${ }^{19}$ & As oxides ${ }^{20}$ \\
\hline Silicon (Si) & $(\mathrm{SiO} 2)$ & 20 & 19.2 & 27 & $14.4-57.7$ \\
\hline Calcium (Ca) & $(\mathrm{CaO})$ & 8 & 30.6 & 21 & $8.9-36.9$ \\
\hline Iron (Fe) & $(\mathrm{Fe} 2 \mathrm{O} 3)$ & 4 & 10 & 8.2 & $2.6-24.4$ \\
\hline Aluminum (Al) & $(\mathrm{Al} 2 \mathrm{O} 3)$ & 7 & 8.9 & 14.4 & $4.6-22.1$ \\
\hline Magnesium (Mg) & $(\mathrm{MgO})$ & 2 & 2.7 & 3.2 & $0.8-2.2$ \\
\hline Sodium (Na) & $(\mathrm{Na} 2 \mathrm{O})$ & 0.3 & 0.8 & 0.5 & $0.1-0.7$ \\
\hline Potassium (K) & (K2O) & 0.5 & 1.4 & 0.6 & $0.07-0.7$ \\
\hline Phosphorus & (P2O5) & 6 & 12.3 & 20.2 & $3.9-15.4$ \\
\hline Sulfur (S) & (SO3) & -- & II.I & 0.9 & $0.01-3.4$ \\
\hline Carbon (C) & -- & -- & -- & -- & -- \\
\hline
\end{tabular}

Trace metal concentrations (e.g., lead, cadmium, zinc, copper) found in sludge ash are typically higher than in natural fillers or aggregate. This finding resulted in some reluctance in using these materials. However, many studies (using leaching tests) suggested that these trace metal concentrations are not excessive and cannot be a source of any measurable leaching problem..$^{21-23}$

The SSA sample was collected from a local wastewater treatment plant incinerator was dark brown in color. The soil samples were obtained from a roadside in West Georgia. The soil was reddish brown in color, well graded. The soil was air dried for 24 hours before any testing. The percentages of SSA $(0 \%, 5 \%, 7.5 \%$, and $10 \%)$ in the soilSSA mixtures and the curing periods $(0,10,14,28$, and 56 days) were arbitrarily selected for the experiments.

$\mathrm{pH}$ of soil, soil-SSA mixtures, and SSA were measured using $\mathrm{HACH} \mathrm{pH}$ meter with the appropriate probe. Two methods were used to experimentally determine specific gravity of soil and the mixtures. One is performed by water pycnometer (ASTM D854) and the other by the gas pycnometer technique (ASTM D5550). Mechanical sieving was used for the coarse-grained portion materials and Hydrometer Analysis used for the fine-grained portion of the materials for grain size distribution, in accordance with ASTM D2487-06, ASTM D422, D1140 and AASHTO T88 and ASTM D7928-17. The grain size distribution curve for the soil used in this study is presented in Figure 1 . 


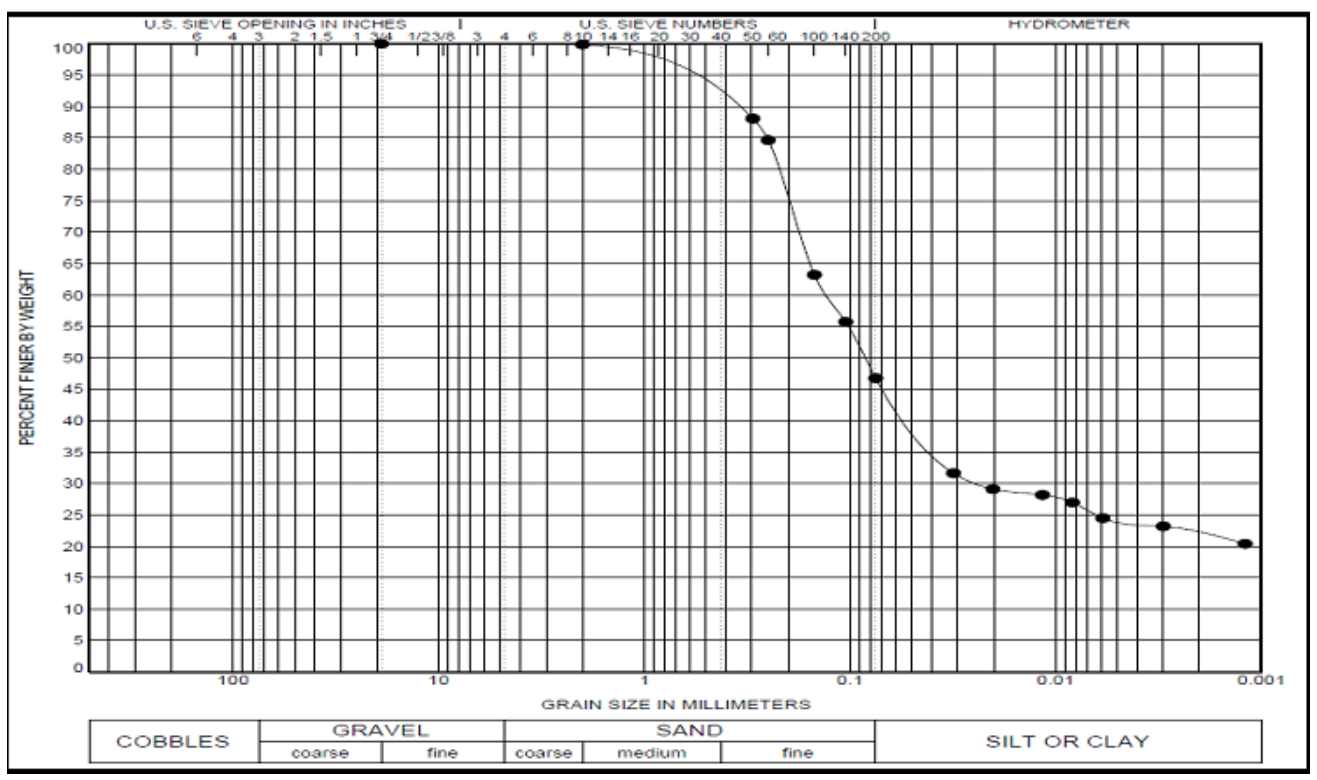

Figure I Grain size distribution curve for the soil used in the study.

Atterberg limits (Liquid Limit - LL, Plastic Limit- PL, and Plasticity Index - PI) tests were performed in accordance with the ASTM D4318. In accordance with the ASTM D698 specification, Standard Test Methods for Laboratory Compaction Characteristics of Soil Using Standard Effort $\left(12,400 \mathrm{ft}-\mathrm{lbf} / \mathrm{ft}^{3}\left(600 \mathrm{kN}-\mathrm{m} / \mathrm{m}^{3}\right)\right)$ were conducted to evaluate the level of compaction of soils, the maximum dry density (MDD), and the optimum moisture content (OMC) for the original soil and the soil mixtures with SSA. In accordance with the ASTM D2166, the unconfined compression strength (UCS) tests were performed for the original soil and the mixtures using the corresponding OMC obtained from the ASTM D698 experiments.
Based on the experimental data (Figure 1), three conditions, such as $\mathrm{R}_{200}, \frac{R 4}{R 200}$, and the values of LL and PI were used to classify the soil, the soil-SSA mixtures, and the SSA in accordance with USCS. The classifications are shown in Table 2. The SSA samples were nonplastic (NP) and finer than the soil. Therefore, the classification of the mixtures changed slightly into different soil types. Based on the USCS, coarse-grained CL changed to coarse-grained ML for 5\% SSA content, and fine-grained ML for $7.5 \%$ and $10 \%$ SSA contents.

Table 2 Classification of the original soil, SSA, and mixtures in accordance with USCS

\begin{tabular}{|c|c|c|c|c|c|}
\hline \multirow{2}{*}{ Soil or mixtures } & \multicolumn{5}{|l|}{ Uscs } \\
\hline & Cond. I & Cond. 2 & & Cond. 3 & Class \\
\hline \multirow[t]{2}{*}{ Original soil (0\% SSA) } & \multirow[t]{2}{*}{$\mathrm{R} 200=53>50$} & $R 4$ & \multirow[t]{2}{*}{$=0<0.5$} & \multirow[t]{2}{*}{$\mathrm{LL}=34 \& \mathrm{Pl}=13$} & \multirow[t]{2}{*}{ Coarse-grained, $\mathrm{CL}$} \\
\hline & & $R 200$ & & & \\
\hline \multirow[t]{2}{*}{ Mixture with 5\% SSA } & \multirow[t]{2}{*}{$R 200=51>50$} & $R 4$ & \multirow[t]{2}{*}{$=0<0.5$} & \multirow[t]{2}{*}{$\mathrm{LL}=30 \& \mathrm{PI}=5$} & \multirow[t]{2}{*}{ Coarse-grained, ML } \\
\hline & & $R 200$ & & & \\
\hline \multirow[t]{2}{*}{ Mixture with $7.5 \%$ SSA } & \multirow[t]{2}{*}{$R 200=49<50$} & $R 4$ & \multirow[t]{2}{*}{$=0<0.5$} & \multirow[t]{2}{*}{$\mathrm{LL}=28 \& \mathrm{PI}=4$} & \multirow[t]{2}{*}{ Fine-grained, ML } \\
\hline & & $R 200$ & & & \\
\hline \multirow[t]{2}{*}{ Mixture with $10 \%$ SSA } & \multirow[t]{2}{*}{$\mathrm{R} 200=48<50$} & $R 4$ & \multirow[t]{2}{*}{$=0<0.5$} & \multirow[t]{2}{*}{$\mathrm{LL}=25 \& \mathrm{Pl}=3$} & \multirow[t]{2}{*}{ Fine-grained, ML } \\
\hline & & $R 200$ & & & \\
\hline \multirow[t]{2}{*}{ SSA } & \multirow[t]{2}{*}{$R 200=2<50$} & $R 4$ & \multirow[t]{2}{*}{$=0<0.5$} & \multirow[t]{2}{*}{ NP } & \multirow[t]{2}{*}{ NP } \\
\hline & & $R 200$ & & & \\
\hline
\end{tabular}


In order to classify the soil, the soil-SSA mixtures, and the SSA in accordance with AASHTO soil classification system, three conditions, such as $\mathrm{F}_{200}$, LL value, and $\mathrm{PI} \leq \mathrm{LL}-30$ or PI $>\mathrm{LL}-30$ were used. A group index was also calculated and provided in parenthesis. The classifications were shown in Table 3. The SSA was non-plastic
(NP) and finer than the soil. Therefore, similar to the USCS, the classification of the mixtures changed into different categories to some extent. Based on the AASHTO soil classification system, A-76 (3) soil converted to soil type A-4 (0) for all SSA contents. The addition of SSA with soil definitely improved the soil type.

Table 3 Classification of the original soil, SSA, and mixtures in accordance with AASHTO

\begin{tabular}{lllll}
\hline \multirow{2}{*}{ Soil or mixtures } & \multicolumn{2}{l}{ AASHTO classification } & \\
\cline { 2 - 5 } & Cond. I & Cond. 2 & Cond. 3 & Class (Group Index) \\
\hline Original soil (0\% SSA) & $\mathrm{F} 200=47>35$ & $\mathrm{LL}=34<40 ; \mathrm{Pl}=\mathrm{I} 3>\mathrm{II}$ & $\mathrm{PI}=\mathrm{I} 3>\mathrm{LL}-30=4$ & $\mathrm{~A}-7-6(3)$ \\
Mixture with 5\% SSA & $\mathrm{F} 200=49>35$ & $\mathrm{LL}=30<40 ; \mathrm{PI}=5<1 \mathrm{I}$ & $\mathrm{PI}=5>\mathrm{LL}-30=0$ & $\mathrm{~A}-4(0)$ \\
Mixture with 7.5\% SSA & $\mathrm{F} 200=5 \mathrm{I}>35$ & $\mathrm{LL}=28<40 ; \mathrm{PI}=4<10$ & $\mathrm{PI}=4>\mathrm{LL}-30=-2$ & $\mathrm{~A}-4(0)$ \\
Mixture with 10\% SSA & $\mathrm{F} 200=52>35$ & $\mathrm{LL}=25<40 ; \mathrm{Pl}=3<10$ & $\mathrm{Pl}=3>\mathrm{LL}-30=-5$ & $\mathrm{~A}-4(0)$ \\
SSA & $\mathrm{F} 200=98>35$ & $\mathrm{NP}$ & $\mathrm{NP}$ & $\mathrm{NP}$
\end{tabular}

\section{Results and discussions}

The test data were analyzed, plotted, and explained to determine the engineering properties of the soil-SSA mixtures that could be used in a wide range of engineering applications. The soil was acidic when compared with the SSA, as shown in Figure 2. This phenomenon can be attributed to a saturation of calcium ions, impacting both the $\mathrm{pH}$ value and the soil treatment mechanism. Calcium ions gradually decrease in concentration as the hydration reaction in treated soil begins. In the beginning, SSA with amounts of calcium mixed with untreated soil leads to high $\mathrm{pH}$ values for treated soil. As the hydration reaction begins, the calcium ions are slowly depleted, and thus the calcium ion saturation in the treated soil is reduced. The soil treated with SSA (mixtures) were less acidic that would be less corrosive to structures and other engineering constructions if the mixtures are used in structural fill. As seen in Figure 2, the specific gravity of the soil, the SSA, and the soil-SSA mixtures varied from 2.49 to 2.67 with a value of 2.65 for SSA which is within the range reported in several studies..$^{10,20}$ The specific gravity of the soil slightly decreased as the percentage of SSA content in the mixture increased because the specific gravity of the SSA was slightly lower than the specific gravity of the original soil.

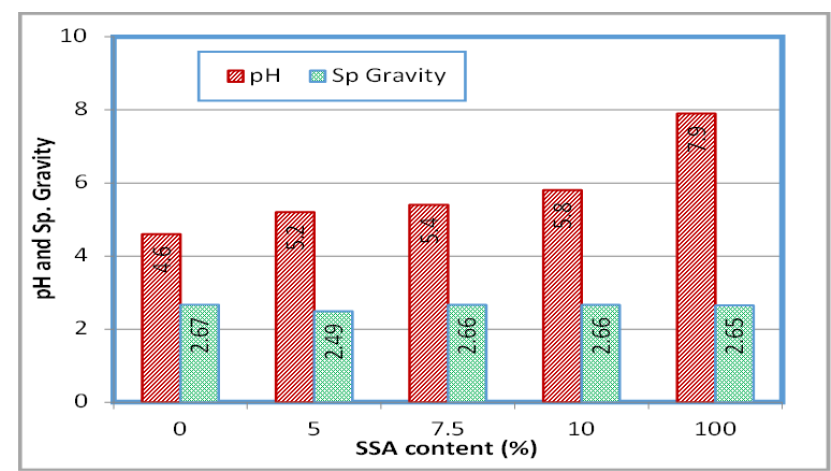

Figure 2 Variations of $\mathrm{pH}$ and Sp. Gravity with SSA content.

The variations of optimum moisture content (OMC), maximum dry density (MDD) with SSA content within the soil are presented in Figure 3 and Figure 4. As seen from Figure 3 and Figure 4, the OMC varied from $11.9 \%$ to $14.2 \%$ and the MDD varied from 114.8 to 120.3 pcf. The original soil had the lowest OMC compared to that of the
soil-SSA mixtures. OMC had a positive correlation with SSA content. Whereas the original soil had the highest MDD compared to that of the soil-SSA mixtures and it had a negative correlation with SSA content. This could be due to the fact that higher SSA contents required more OMC (Figure 3), moisture contents in the mixtures increased the test sample volume, and hence provided the lower MDD. These test results did not provide any reason or validation to select an optimum SSA content from a compactability/workability point of view. These findings followed similar patterns provided in couple of studies. ${ }^{8,24}$

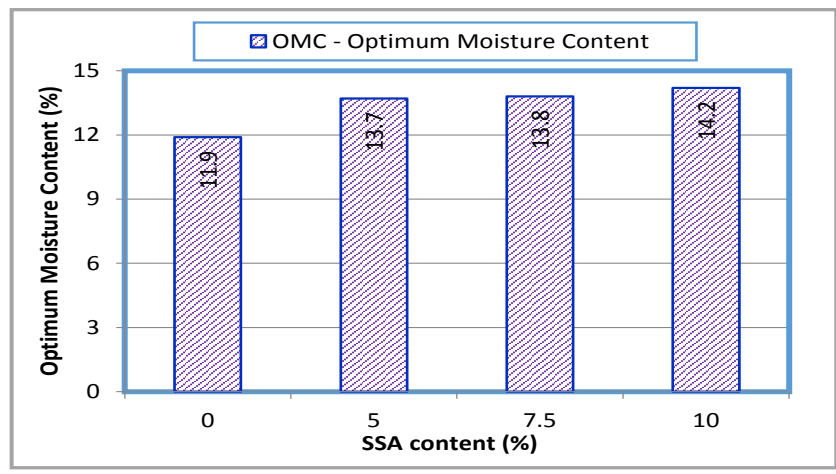

Figure 3 Variations of OMC with SSA content.

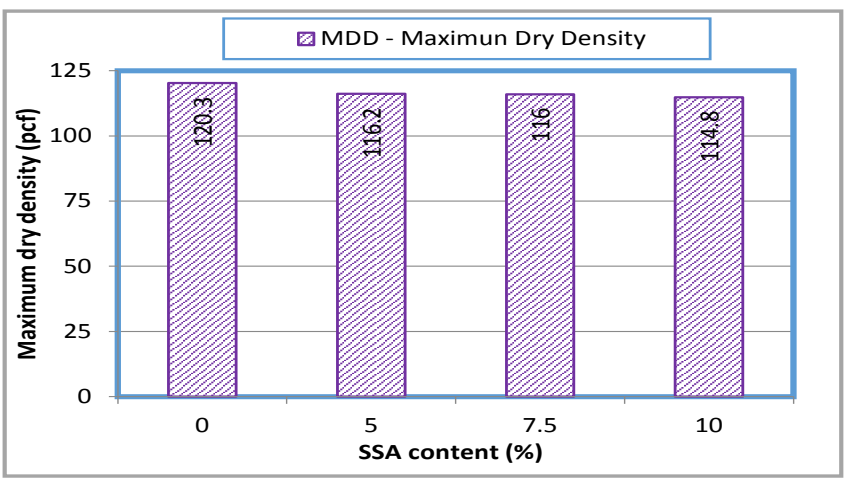

Figure 4 Variations of MDD with SSA content.

Figure 5 represents the variations of unconfined compressive strengths for the original soil and the soil-SSA mixtures compacted at the corresponding optimum moisture content (Figure 3) for the curing 
periods of $0,10,14,28$, and 56 days at room temperature $30 \pm 3^{\circ} \mathrm{C}$. Other than air drying in the lab, the samples received no special treatment during the curing process. This condition could be simulated in the field by covering the subgrade with tarp and allowing it to dry for the desired curing period. The results showed an increase of compressive strength of the treated soils (all mixtures) consistently throughout the curing period, which is consistent with a study conducted by Luo et al. ${ }^{16}$ However, the observed increase of compressive strengths for all mixtures from 28 to 56 days was not that significant (only 6-11\%) based on the 28 days separation of the curing period. Therefore, a curing period of 28 days could be considered as an optimum for soil-SSA mixtures. The increase of compressive strengths with the increase of SSA contents could be due to the chemical reaction of the SSA with the soil represented by the deposition of some mineral such as Calcium Carbonate inside the pores of soil-SSA matrix that resulted in plugging the pores in the mixture resulting in reducing the soil permeability and increasing its strength. Another potential reason could be the contribution of the angular glassy spheres of SSA grains which increased the bonds among soil particles.

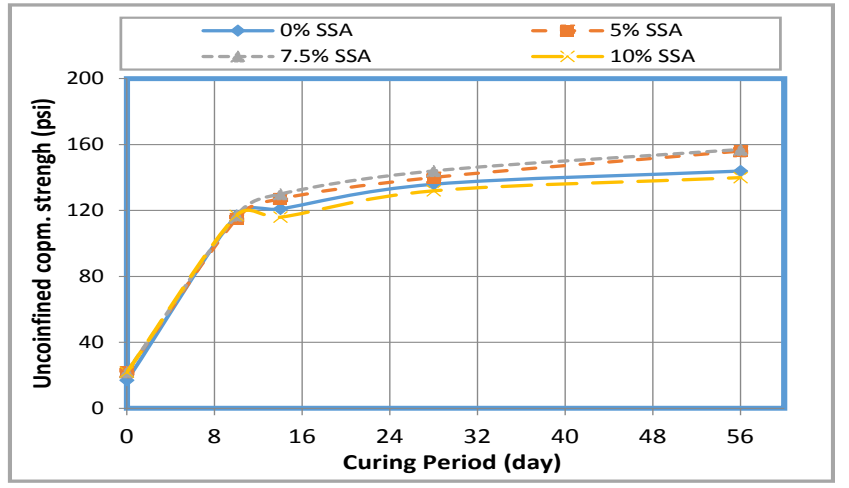

Figure 5 Variation of unconfined compressive strength with curing period.

The variations of unconfined compressive strengths (UCS) with SSA content for different curing periods are shown in Figure 6. It is seen in this Figure that soil and all mixtures gained significant strength (about 100psi) in 10 days. Whereas, after 10days, the gain is not that significant (between 20-40psi). UCS showed a peak for $7.5 \%$ SSA content for curing periods of 14,28 and 56 days. The rest showed almost flat for all SSA contents. No strength was gained right after mixing and started gaining strength with time. UCS appeared to decrease after $7.5 \%$ content for three curing periods (14-, 28-, and 56-day) that is consistent with a study conducted by Lynn et al. ${ }^{13}$ However, several other studies reviewed by Lynn et al. ${ }^{13}$ provided contradictory results. According to a few studies, ${ }^{9,25}$ the contents of $\mathrm{SiO}_{2}(17.27-50.60 \%)$ and $\mathrm{Al}_{2} \mathrm{O}_{3}(6.32-19.09 \%)$ in SSA indicated that SSA may be pozzolanic with the potential to be used as supplementary cementitious material (SCM). There are numerous direct and indirect methods for determining the pozzolanic activity of a material. ${ }^{25}$ To date, most research has used indirect methods, i.e. recording the effects of substituting part of the cement content by SSA on mortars and pastes on compressive strength. Adverse effects are attributed to increased water requirements due to the irregular morphology of SSA particles. ${ }^{26}$ Using direct methods, Jamshidi et al. ${ }^{27}$ determined the pozzolanic activity of SSA to be $37.86 \%$, while Fontes et al. ${ }^{28}$ derived a value of $70.53 \%$. Therefore, pozzolanic materials in SSA may attribute to the increase in UCS of the treated soils by SSA. Since a curing period of 28 days seemed to be an optimum (Figure 5), 7.5\% SSA content appeared to be the optimum soil-SSA mixture to provide maximum strength. However, based on the data for curing periods of 28 and 56 days, the $5 \%$ SSA content could be a viable alternative.

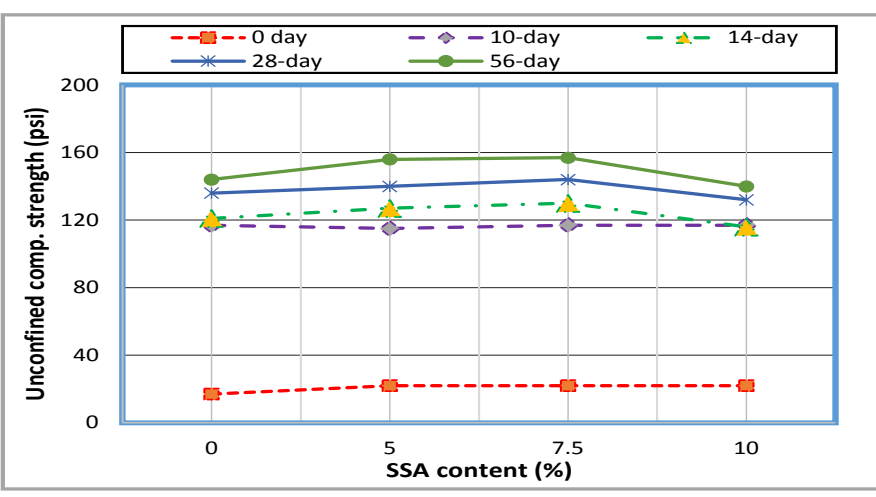

Figure 6 Variation of unconfined compressive strength with SSA content.

The variations of Atterberg Limits (LL, PL, and PI) with SSA content are presented in Figure 7. As seen in this Figure, the LL of the original soil was the highest, followed by the mixture with 5\% SSA, the mixture with $7.5 \%$ SSA, and the mixture with $10 \%$ SSA. The PL for the mixture with $5 \%$ was the highest, followed by the mixture with $7.5 \% \mathrm{SSA}$, the mixture with $10 \% \mathrm{SSA}$, and the original soil. The decrease of the PL could be attributed to the multivalent cations $\left(\mathrm{Ca}^{2+}\right.$, $\mathrm{Fe}^{3+}$, and $\mathrm{Al}^{3+}$ ) provided by the SSA work on displacing monovalent cations $\left(\mathrm{Mg}^{2+}>\mathrm{Ca}^{2+}>\mathrm{Na}^{+}>\mathrm{K}^{+}\right)$, the abundance of multivalent cations changes the soil particles' electrical charge which causes the soil particles attracted to each other. The electrical attraction of soil particles aids the flocculation and is attributed to the change in soil nature (granular nature after flocculation and agglomeration) and resulted in reduced soil plasticity. The original soil showed the highest PI (13\%), followed by the mixture with 5\% SSA (5\%), the mixture with $7.5 \% \mathrm{SSA}(4 \%)$, and the mixture with $10 \% \mathrm{SSA}(3 \%)$, which is consistent with a similar study conducted by Luo et al. ${ }^{16}$

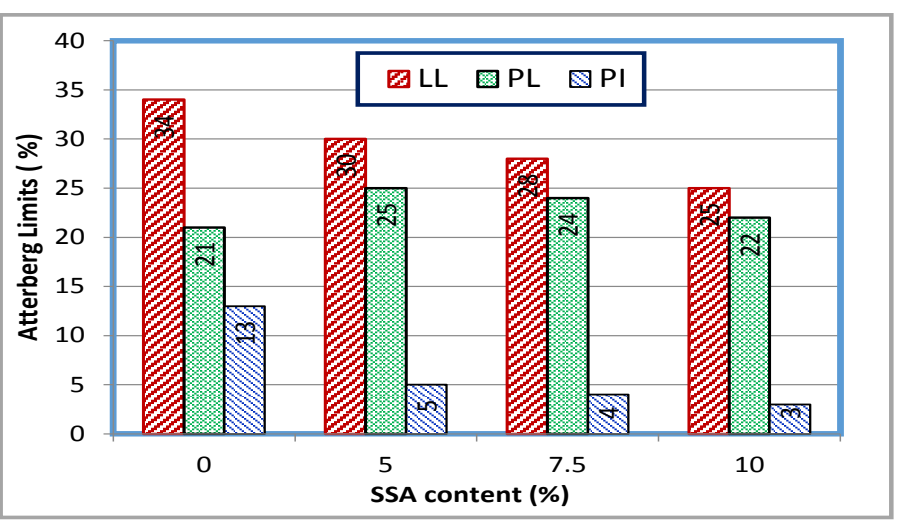

Figure 7 Variation of plasticity index with SSA content.

$\operatorname{Das}^{29}$ pointed out that the swell potential of soil is related to soil activity. The higher the soil activity value, the greater the soil swell potential. Similarly, the soil activity is also related to the PI value. The higher the PI value, the greater the soil swell potential. As stated above, when part of the clay in untreated soil was replaced by SSA, the PI value of treated soil decreased. This decrease leads to a reduction in volumetric swelling in treated soil, which coincided with Das' finding. Furthermore, Seed et al. ${ }^{30}$ and Mitchell ${ }^{31}$ proposed and used a relationship between percent swelling (S) and PI value, $S=2.16 \times 10^{-3}(P I)^{2.44}$ Thus, volumetric swellings for the SSAtreated soil could be considered decreased as the PI values decreased. The PI values of SSA-treated soil in this study were smaller than that of untreated soil (Figure 7) and PI values decreased with increased 
SSA contents, which could lead to a more pronounced reduction in volumetric swelling according to $\mathrm{S}$ and PI relationship. This finding is consistent with a study conducted by Al-Sharif and Attom. ${ }^{17}$

\section{Conclusion}

The specific gravity of the mixtures decreased as the percentages of SSA content in the mixture increased. This could be because of the specific gravity of the SSA was lower than the specific gravity of the original soil. Due to these characteristics, SSA occasionally was utilized in making light-weight concrete. The addition of 5\%, $7.5 \%$, and $10 \%$ SSA with coarse-grained CL soil type [A-7-6 (3)] converted to fine-grained ML soil type [A-4 (0)]. The soil treated/ mixed with SSA resulted in less acidic that would be less corrosive to structures and other engineering constructions if they were to be used in structural fill. Based on the OMC and MDD values, both the soil and mixtures with all SSA contents seemed to be acceptable in terms of providing compaction. Therefore, the addition of SSA to the CL soil [A-7-6(3)] improved the compaction properties of the soil. Based on the UCS values, both the mixtures with $5 \%$ and $7.5 \%$ SSA contents seemed to be better in terms of providing strengths. In accordance with PI values, the mixture with the original soil seemed to be better in terms of compatibility. It can be concluded from this study that a mixture of soil with $7.5 \%$ SSA content and a curing period of 28days seemed to be an optimum and better option for engineering uses. However, a mixture with 5\% SSA content and the same curing period could be used as a viable alternative. The volumetric swelling potential decreased with increased SSA contents. Potentially about $7.5 \%$ of SSA can be utilized as a beneficial use that would go to landfill to be managed otherwise.

\section{Acknowledgments}

The authors acknowledge the stipend for a graduate student from the Graduate College of Kennesaw State University in the form of Graduate Research Assistantship (GRA).

\section{Funding}

This research received no external funding.

\section{Conflicts of interest}

The authors declare there are no conflicts of interest.

\section{References}

1. Federal Highway Administration (FHWA). User guidelines for waste and byproduct materials in pavement construction. FHWA-RD. 2019:97-148.

2. Odegaard B, Paulsrud H, Karlsson I. Wastewater sludge as a resource: sludge disposal strategies and corresponding treatment technologies aimed at sustainable handling of wastewater sludge. Water Sci Technol. 2002;46(10):295-303.

3. Fytili D, Zabaniotou A. Utilization of sewage sludge in EU application of old and new methods - a review. Renew Sustain. Energy Rev 2008;12:116-140.

4. Lin WY, Ng WC, Wong BSE, et al. Evaluation of sewage sludge incineration ash as a potential land reclamation material. $J$ Hazard Mater. 2018;357:63-72.

5. Pérez-Carrión M, Baeza-Brotons F, Payá J, et al. Potential use of sewage sludge ash (SSA) as a cement replacement in precast concrete blocks. mater. Constr. 2014;64(313).
6. Rutkowska G, Wichowski P, Fronczyk J, et al. Use of fly ashes from municipal sewage sludge combustion in production of ash concretes. Constr Build Mater. 2018;188:874-883.

7. Lin KL, Lin CY. Hydration characteristics of waste sludge ash utilized as raw cement material. Cem Concr Res. 2005;35:1999-2007.

8. Baez-Brotons F, Garces PJ, Paya J, et al. Portland cement systems with addition of sewage sludge ash, application in concretes for the manufacture of blocks. J Clean Prod. 2014;82:112-124.

9. Vouk D, Nakic N, Stirmer N, et al. Use of sewage sludge ash in cementious materials. Rev Adv Mater Sci. 2017;49:158-170.

10. Metropolitan Waste Control Commission (MWCC). Sewage sludge ash use in bituminous paving; minnesota department of transportation, Minnesota pollution control agency; 1990.

11. Al-Sayed MH, Madany I, Buali ARM. Use of sewage sludge ash in asphaltic paving mixes in hot regions. Constr Build Mater. 1995;9:19-23.

12. Kosior-Kazberuk M. Application of SSA as partial replacement of aggregate in concrete. Pol J Environ Stud. 2011;20(2):365-370.

13. Lynn CJ, Dhir RK, Ghataora GS, et al. Sewage sludge ash characteristics and potential for use in concrete. Constr Build Mater. 2015;98:767-779.

14. Kappel A, Viader RP, Kowalski KP, et al. Utilization of electrodialytically treated sewage sludge ash in mortar. Waste Biomass Valorization. 2018.

15. Chen L, Lin DF. Stabilization treatment of soft subgrade soil by sewage sludge ash and cement. J Hazard Mater. 2009;162(1):321-327.

16. Luo HL, Hsiao DH, Lin DF, et al. Cohesive soil stabilized using sewage sludge ash/cement and nano aluminum oxide. Int J Transp Sci Technol. 2012;1(1):83-100.

17. Al-Sharif MM, Attom FM. A geoenvironmental application of burned wastewater sludge ash in soil stabilization. Environ Earth Sci. 2014;17(5):2453-2463.

18. Lin DF, Huang MJ, Luo HL. Sludge ash/hydrated lime on the geotechnical properties of soft soil. J Hazard Mater. 2007;145(1-2):58-64.

19. Wegman DE, Young DS. Testing and evaluating sewage sludge ash in asphalt paving mixtures. 1988 .

20. Gray DH, Penessis C. Engineering properties of sludge ash. $J$ Water Pollut Control Fed. 1972;44(5):47-858.

21. Braun Intertec Environmental. Sewage sludge ash use in bituminous paving; report on additional testing., prepared for metropolitan Waste control commission; metropolitan Waste control commission; 1991.

22. Braun Intertec Environmental. Sewage sludge ash use in bituminous paving; report on additional testing, prepared for metropolitan Waste control commission; metropolitan Waste control commission; 1992.

23. Khanbiluardi RM. Ash use from suffolk county wastewater treatment plant; sewer district No. 3. City University of New York: Draft Report; 1994

24. DeLima JF, Ingunza D, Del Pilar M. Effect of sewage sludge ash addition in portland cement concretes. International Conference on Civil, Materials, and Environmental Science (CMES); Atlantis Press: London; 2015:189-191.

25. de Azevedo Basto P, Junior HS, de Melo Neto AA. Characterization and pozzolanic properties of sewage sludge ashes (SSA) by electrical conductivity. Cem Concr Compos. 2019;104:103410.

26. Donatello $\mathrm{S}, \mathrm{Cheeseman} \mathrm{CR}$. Recycling and recovery routes for incinerated sewage sludge ash (ISSA): a review. Wste Manag. 2013;33(11):23282340 . 
27. Jamshidi A, Mehrdadi N, Jamshidi M. Application of sewage dry sludge as fine aggregate in concrete. J Environ Stud. 2011;37(59).

28. Fontes Filho JP, Gonclaves Fontes CMA, Barbos MC, Toledo RD Proceedings of the Intern. RILEM conference on the use of recycled materials in buildings and structures; 2004. 797 p.

29. Das BM. Principle of geotechnical engineering, 5th edn. Thomson Co.: Nelson: Toronto, ON, Canada; 2002.
30. Seed HB, Woodward J, Lundgren R. Prediction of swelling potential for compacted clays. J Soil Mech Found Div. 1962;88(3):53-87.

31. Mitchell, J. K. Fundamentals of soil behavior. Hoboken, NJ, USA: John Wiley \& Sons, Inc; 1993. 